\title{
Assessing Land Use Planning Tools to Mitigate Odour and Lighting Nuisances Related to Cannabis Production
}

Dr Sara Epp

Dr Wayne Caldwell Alessia Pugliese Jordan Scholten

Samantha Yeung 


\section{Why Research Can
Cultivation Policy?}

- Rapid expansion into Southern Ontario predominantly in the rural country-side

- Although there are potential economic benefits, lighting and odour nuisances' impact nearby dwellings

- The novelty of cannabis legalization poses a gap in current research, that this project aims to address

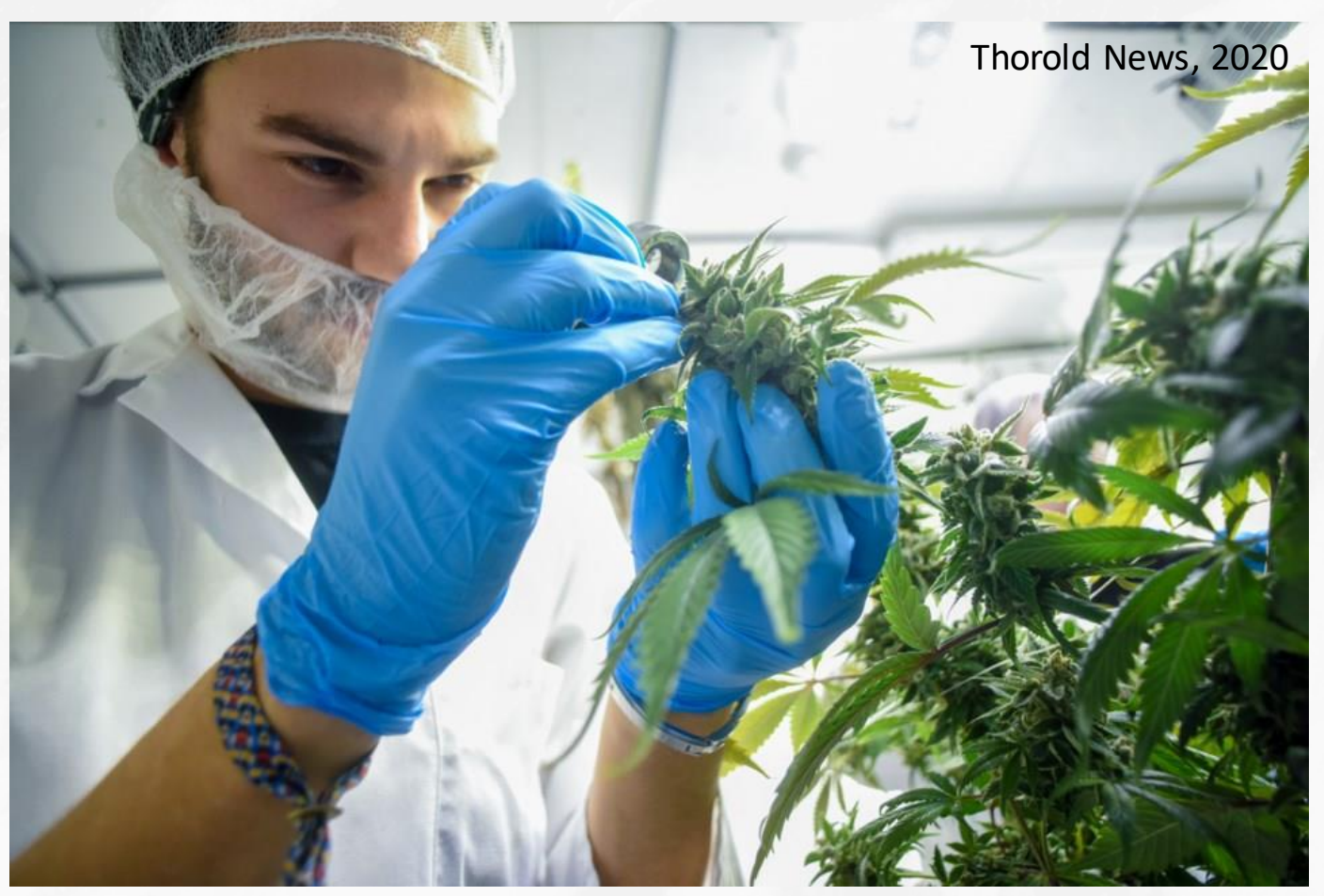




\section{Jurisdictional Analysis: Overarching Themes}

Zoning By-law policies

- Analyzing setback requirements

- Zoning: Agricultural vs Industrial

- Proximity to other land uses

Themes

- Inconsistency

- Zoning trends

\begin{tabular}{|l|l|l|}
\hline \multicolumn{1}{|c|}{ Municipality } & \multicolumn{1}{|c|}{ Setback } & \multicolumn{1}{c|}{ Zone } \\
\hline $\begin{array}{l}\text { Niagara-on-the-lake, } \\
\text { Niagara }\end{array}$ & 600m from the property line & Agricultural \\
\hline $\begin{array}{l}\text { Grimsby, Niagara } \\
\text { (unofficially) }\end{array}$ & $\begin{array}{l}\text { 150m from residential and } \\
\text { industrial zone }\end{array}$ & Agricultural, Rural \\
\hline Pelham, Niagara & $\begin{array}{l}300 \mathrm{~m} \text { from sensitive land } \\
\text { use }\end{array}$ & $\begin{array}{l}\text { Agricultural } \\
\text { \& Industrial }\end{array}$ \\
\hline Melancthon, Dufferin & $\begin{array}{l}\text { 2000m from another } \\
\text { cannabis facility \& SA } \\
300 \mathrm{~m} \text { from dwelling }\end{array}$ & Agricultural \\
\hline
\end{tabular}




\section{Local Planning Appeals Tribunals}

\section{(LPAT)}

- Current LPATs: Oro-Medonte, Enniskillen, County of Norfolk (x2), Town of Caledon, Town of NOTL, City of Hamilton, New Tecumseth

Most Common Themes:

o Town-wide versus Site Specific Amendments

o Issues with set-backs

- Issues with Interim Control By-laws 


\section{Next Steps:}

o Interviews with municipal authorities, producers, adjacent landowners, and other stakeholders

- Case Studies in various municipalities

- Policy database relating to cannabis zoning bylaws 
Thankyou to OMAFRA for funding through the Ontario Agri-Food Research Alliance 


\section{Questions?}

